\title{
Characteristics of admissions with diabetic ketoacidosis in a specialized children hospital: Missing insulin is still a challenge!
}

\author{
Amir Babiker ${ }^{1}$, Ghadeer Aljahdali ${ }^{2}$, Mohammed Alsaeed ${ }^{2}$, Abdulrahman Almunif ${ }^{2}$, \\ Mohamud Mohamud ${ }^{2}$, Omer Abid ${ }^{3}$, Mohammed Al Dubayee ${ }^{1}$, Fahad Al Juraibah ${ }^{1}$, \\ Angham Al Mutair ${ }^{1}$, and Ibrahim Al Alwan ${ }^{1}$ \\ ${ }^{1}$ King Abdullah Specialized Children's Hospital, King Abdulaziz Medical City, Ministry of \\ National Guard Health Affairs \\ ${ }^{2}$ King Saud bin Abdulaziz University for Health Sciences \\ ${ }^{3}$ King Abdullah International Medical Research Center
}

June 10, 2020

\begin{abstract}
Aim: To assess the characteristics of admissions with diabetic ketoacidosis (DKA) in a specialized children hospital in order to inform appropriate prevention and intervention strategies. Methods: This is a retrospective chart review of DKA admissions of children with T1DM at King Abdullah Specialized Children's hospital, Riyadh, Saudi Arabia (March 2015- December 2017). Results: A total of 116/562 patients with type 1 diabetes (mean age $8.97 \pm 3.08$ years, Females $\mathrm{n}=81(55.5 \%)$ ) presented with DKA during the study period. The majority were between $10-14$ years of age $(\mathrm{p}=<0.001)$. We scrutinized data from (146/311, $47 \%$ ) DKA events of all inpatient admissions of children with T1D. The frequency of DKA admissions was $26 \%$ ( $\mathrm{n}=146 / 562$ of all patients with T1DM, 25\% ( $\mathrm{n}=42 / 141)$ were in newly diagnosed and 24.7\% ( $\mathrm{n}=104 / 421)$ were in previously diagnosed patients). Missing insulin was the main precipitating cause $(\mathrm{p}=0.001)$ in previously diagnosed patients. Recurrent episodes $(\mathrm{n}=30,20.5 \%$ of all episodes) occurred in 15/116 patients and was more common in children ?10 years old $(\mathrm{P}=0.024)$. The overall mean length of stay (LOS) was $2.67+-2.04$ days. Increased LOS was significantly associated with DKA severity $(\mathrm{P}=0.008)$. Conclusion: Missing insulin remained to be the main cause of DKA in previously diagnosed patients with type 1 diabetes even in advanced settings. Besides awareness campaigns to prevent DKA as an initial presentation of T1DM, intervention and prevention strategies should also focus on vulnerable groups of previously diagnosed patients such as adolescents and those with recurrent episodes of DKA.
\end{abstract}

\section{Hosted file}

DKA_Main_Document_10Jun20.docx available at https://authorea.com/users/331920/articles/ 458409-characteristics-of-admissions-with-diabetic-ketoacidosis-in-a-specializedchildren-hospital-missing-insulin-is-still-a-challenge 
Figure 1 - Frequency of DKA in newly and previously diagnosed patients

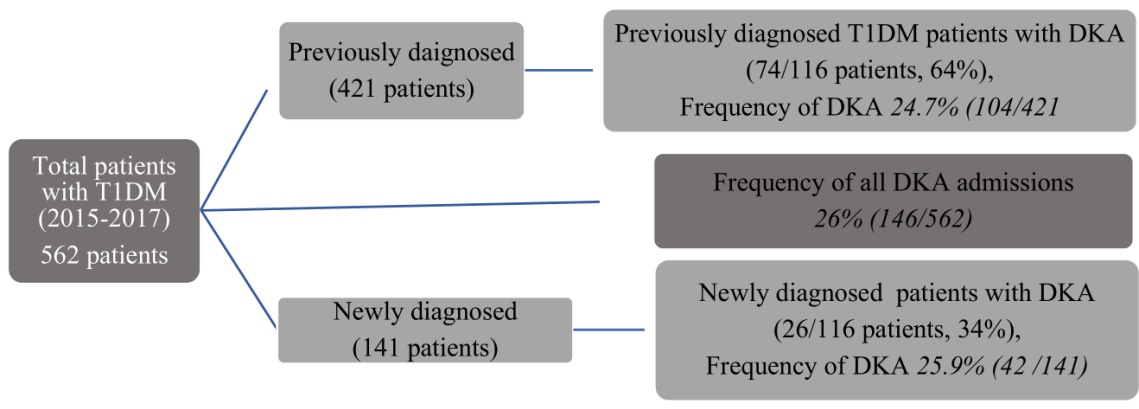

DKA-Diabetic ketoacidosis; T1DM-Type 1 diabetes mellitus

Figure 2 - Precipitating factors of diabetic ketoacidosis in previously diagnosed patients

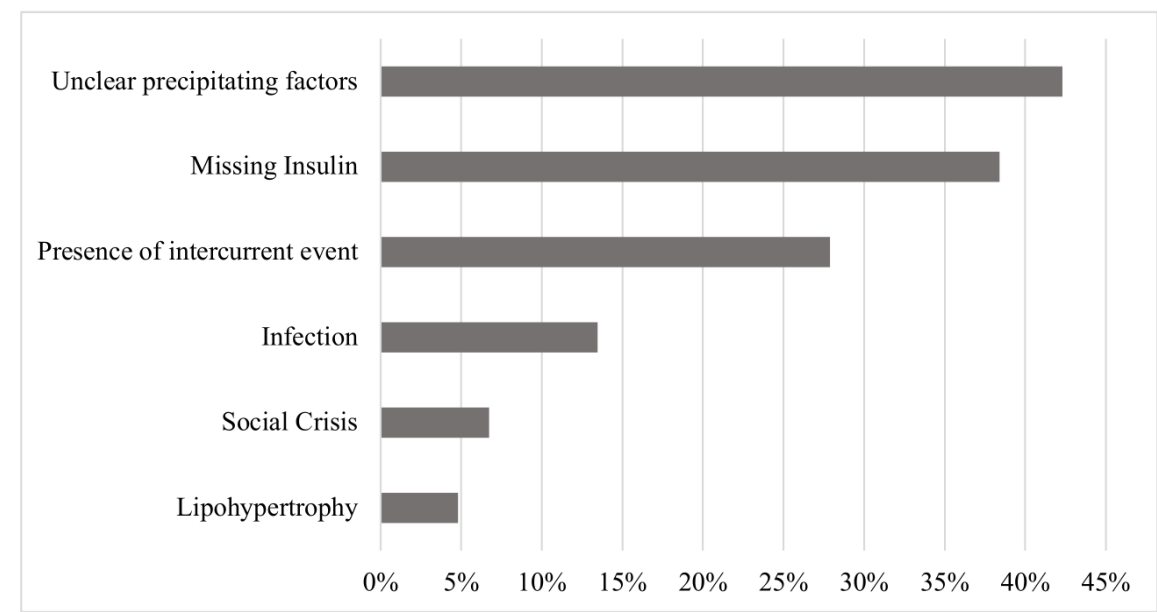

\section{Hosted file}

Table 1.docx available at https://authorea.com/users/331920/articles/458409-characteristicsof-admissions-with-diabetic-ketoacidosis-in-a-specialized-children-hospital-missinginsulin-is-still-a-challenge

\section{Hosted file}

Table 2.docx available at https://authorea.com/users/331920/articles/458409-characteristicsof-admissions-with-diabetic-ketoacidosis-in-a-specialized-children-hospital-missinginsulin-is-still-a-challenge

\section{Hosted file}

Table 3.docx available at https://authorea.com/users/331920/articles/458409-characteristicsof-admissions-with-diabetic-ketoacidosis-in-a-specialized-children-hospital-missinginsulin-is-still-a-challenge 